\title{
Investigation of brachial plexus traction lesions by peripheral and spinal somatosensory evoked potentials
}

\author{
S. J . J O N E S \\ From the Institute of Neurology, The National Hospital, Queen Square, London
}

S U M M ARY Peripheral, spinal and cortical somatosensory evoked potentials were recorded in 26 patients with unilateral traction injuries of the brachial plexus, to estimate the degree of involvement distal and proximal to the dorsal root ganglia. Of 10 cases explored surgically the recordings correctly anticipated the major site of the lesion in eight.

The brachial plexus and associated spinal roots are particularly prone to injury in accidents which involve a violent traction of the arm. The outcome may be a partial or complete anaesthesia of the forearm and hand, the segmental distribution usually corresponding to that of the fifth cervical (C5) to the first thoracic (T1) roots, with motor loss and wasting in the same distribution. In such cases it is important to establish the location of the lesion in the brachial plexus, the spinal nerves, or the roots adjacent to the spinal cord, since this can influence the prognosis and the prospects of reconstructive surgery (Drake, 1964).

Investigative techniques which may assist in distinguishing between an avulsed root, ruptured at the point of entry to the spinal cord, and a more distal lesion include myelography (Davies et al., 1966), electromyography with sensory action potential (SAP) recording (Bonney and Gilliatt, 1958; Warren et al., 1969), and examination of the axon reflex response to subdural histamine injection (Bonney, 1954). The latter two techniques depend on the location of the dorsal root and sympathetic ganglia in the spinal canal external to the spinal cord, such that the sensory and sympathetic axons in the peripheral nerve may be preserved when the rupture is on the proximal side of the ganglia. The prognosis for such a lesion is, however, very poor, whereas with a rupture in the brachial plexus or the spinal nerves distal to the ganglia axonal regeneration may

Address for correspondence and reprint requests: Dr S. J. Jones, Institute of Neurology, The National Hospital, Queen Square, London WC1N 3BG.

Accepted 18 August 1978 sometimes be assisted by anastomosis or nerve graft.

By means of signal averaging techniques and median nerve stimulation at the wrist it is possible to record somatosensory evoked potentials (SEPs) generated in the brachial plexus (Jones, 1977a), spinal cord, or brainstem (Cracco, 1973; Matthews et al., 1974; Jones, 1977b), and sensory cortex (Dawson, 1947; Giblin, 1964; Goff et al., 1977). The present SEP study was undertaken in order to supplement existing, relatively indirect, methods of distinguishing between traction lesions distal and proximal to the dorsal root ganglia.

\section{Methods}

Stimulation and recording techniques were similar to those previously described (Jones, 1977b). A capacitor discharge, time constant $50 \mu \mathrm{s}$, was delivered at a rate of two per second to the median nerve at the wrist. Silver/silver chloride disc electrodes were applied to the skin overlying the clavicles, upper cervical vertebrae (Cv2-4), and the Rolandic (parietal) somatosensory cortex with a common midfrontal reference (Fz, 10-20 system). The amplifier frequency response was better than $-3 \mathrm{~dB}$ at $5 \mathrm{kHz}$, with a time constant of 1.0 second. Potentials evoked by up to 1600 stimuli were sumued in groups of 400 on three or more channels simultaneously, with a sampling rate of $8.0 \mathrm{kHz}$.

The subjects were awake and reclining in an armchair. Fourteen normal control subjects (three men, 11 women) had a mean age of 25.6 years with a range of $20-32$ years. Twenty-six patients (23 
male, three female, mean age 20.7 years) were aged between 6 and 41 years although the majority (15) were between the ages of 17 and 20 years. The brachial plexus injury was unilateral, and sustained through motor cycle (22 cases), car (three), and industrial (one) accidents. The left arm was involved in 14 cases and the right arm in 12 .

The stimulus intensity was set at two to four times the subjective sensory threshold voltage on the intact side, the exact strength being adjusted so as to produce a moderate twitch of the hand and a recording in which the three major potentials (see below) were clearly visible. This setting was also employed on the injured arm, but where the stimulus was not perceived and evoked potentials were greatly attenuated or absent a stimulus of up to three times the standardised voltage was employed on this side only. In the normal control subjects the stimulus voltage was set using the left arm in 10 cases and the right in four, and employed at the same intensity on either side.

The SEPs studied were the three most prominent negative-going potentials with peak latency less than $25 \mathrm{~ms}$. These have been labelled (Goff et al., 1977; Jones, 1977b): N9, maximal over the clavicle of the stimulated arm; N13, maximal over the cervical vertebrae; N20, maximal over the somatosensory cortex contralateral to the stimulated arm (Fig. 1). The amplitude of N9 was measured from the immediately preceding positive peak, and the amplitude of N13 and N20 from the baseline. Peak latencies were measured from the stimulus triggering pulse.

In 10 cases the location of the lesion was confirmed by exploratory surgery, including seven cases in whom nerve action potentials (NAPs) or SEPs or both were recorded after stimulation of the exposed spinal nerves. The NAPs were recorded from the exposed area of the brachial plexus, and the SEPs from the contralateral scalp. Ruptured roots were also stimulated, where possible, in
J.S. Age: $32 \quad$

Electrode Stimulus

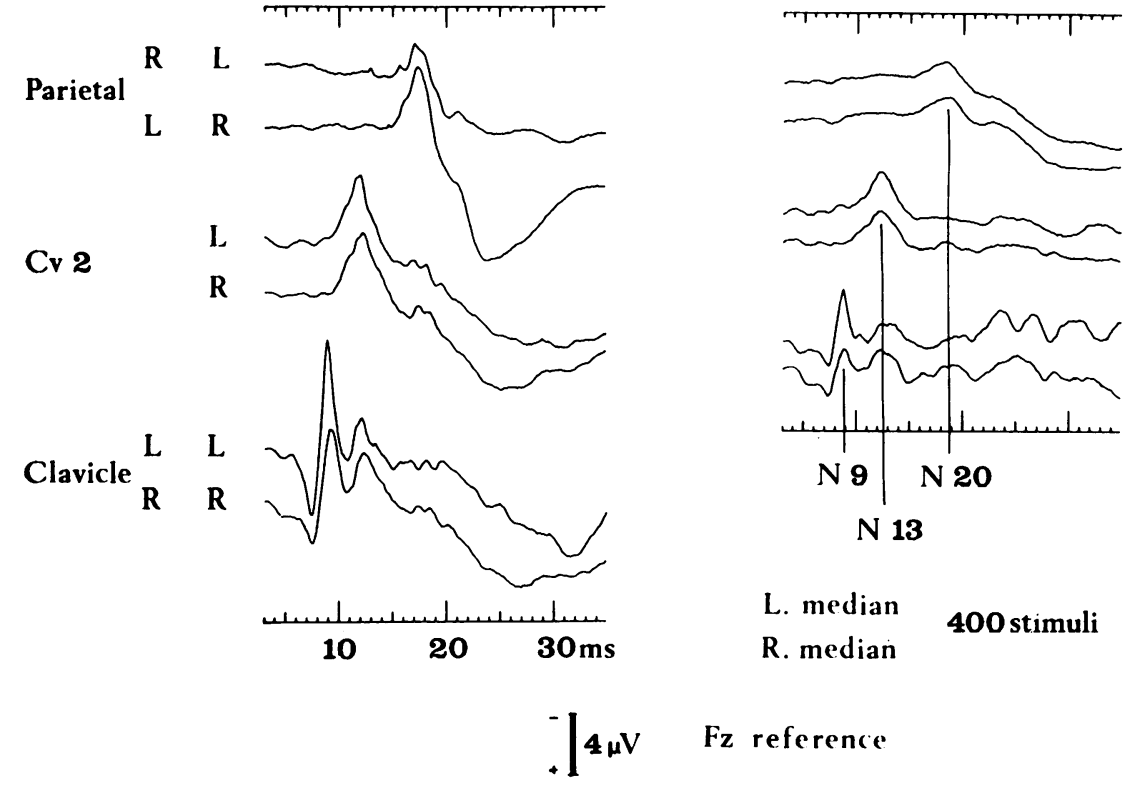

\section{F. R. Age: 28 ○}

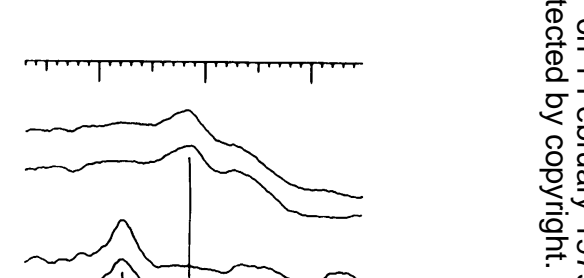

Fig. 1 Somatosensory evoked potentials simultaneously recorded from three electrode locations with a mid-frontal $(F z)$ reference, to stimulation of the left and right median nerve at the wrist in two normal subjects. The electrodes were located over the contralateral somatosensory cortex (parietal), second cervical vertebra $(C v 2)$, and ipsilateral clavicle. These examples were chosen to illustrate the inter-subject and inter-arm amplitude variation of the three major negative-going potentials, N9, N13, and $N 20$. 
order to establish the continuity of a proximal stump with the central nervous system by the presence of SEPs.

\section{Results}

NORMAL SOMATOSENSORY EVOKED POTENTIALS The mean and standard deviation of the amplitude and latency of each potential for the normal control subjects are given in Table 1 , along with the largest differences encountered between left and right arm stimulation. In each individual the left/right amplitude difference for a given potential, expressed as a percentage of the amplitude on the side with the larger response, was less than $40 \%$ for $\mathrm{N} 9$ (extreme case, left $5.9 \mu \mathrm{V}$, right $9.7 \mu \mathrm{V}), 48 \%$ for $\mathrm{N} 13$, and $60 \%$ for $\mathrm{N} 20$. Individual left/right latency differences for each potential were less than $6 \%$ of the latency on the side with the faster response (extreme case, N9; left $10.8 \mathrm{~ms}$, right $10.2 \mathrm{~ms}$ ).

There was a tendency for N13 and N20 to be of larger amplitude with stimulation of the right arm ( $\mathrm{P}<0.05$ for N13, $t$ test for matched samples), this being the case in 10 out of 14 subjects for N13, and nins out of 13 subjects for N20. The N9 amplitude was larger with stimulation on the right in three out of 10 subjects only. The reason for these differences is not known, and further investigation is required with elimination of nonrandom factors (for example stimulation of the left arm first in most subjects).

Corresponding values of mean amplitude and latency for stimulation of the intact arm in the 26 patients (12 left arm, 14 right arm intact) are given in Table 2. The "left arm intact" group differed significantly $(\mathrm{P}<0.02, t$ test for independent samples) from the values for the left arm of the normal control subjects in the increased mean latency of each potential, possibly because of the greater preponderance of males in the patient group, and hence greater mean arm length. There was also a significant reduction $(\mathrm{P}<0.01)$ in the
Table 2 Mean values for the amplitude and latency (士one standard deviation) of three evoked potentials to stimulation of the intact arm in 26 patients with brachial plexus lesions

\begin{tabular}{lllr}
\hline Patient group & Potential & $\begin{array}{l}\text { Amplitude }(\mu V) \\
\text { Mean } \pm S D\end{array}$ & $\begin{array}{l}\text { Latency }(\mathrm{ms}) \\
\text { Mean } \pm S D\end{array}$ \\
\hline Left arm intact & N9 & $7.9 \pm 4.0$ & $10.1 \pm 0.8$ \\
$(\mathrm{n}=12)$ & N13 & $3.0 \pm 0.7$ & $13.7 \pm 0.8$ \\
& N20 & $2.3 \pm 1.3$ & $19.4 \pm 0.9$ \\
Right arm intact & N9 & $6.8 \pm 2.7$ & $9.6 \pm 1.1$ \\
(n=14) & N13 & $2.6 \pm 0.7$ & $13.3 \pm 1.4$ \\
& N20 & $1.8 \pm 0.9$ & $19.0 \pm 1.6$ \\
\hline
\end{tabular}

mean amplitude of N13 for the "right arm intact" group compared with the normal control subjects. In individual cases, however, deviations from the normal range were few and marginal. The responses obtained from the intact arm were employed as a baseline for estimating the attenuation of each component with stimulation of the injured arm. This was to take advantage of the lesser variance that is found between the SEPs to left and right arm stimulation in healthy individuals than across the normal population as a whole.

SOMATOSENSORY EVOKED POTENTIALS IN BRACHIAL PLEXUS LESIONS

On clinical criteria the 26 patients were divided into three groups according to the severity of the lesion: group 1, complete anaesthesia and paralysis of the arm in the distribution of the C5 to T1 segments (13 cases); group 2, involvement corresponding to the $\mathrm{C5}$ to $\mathrm{C7}$ root distribution with minimal C8/T1 impairment (eight cases); group 3, involvement confined to the $\mathrm{C} 5$ and $\mathrm{C} 6$ root distribution (five cases).

Each patient is represented in Fig. 2 by a solid (in one case broken) line to indicate the degree of attenuation of the major potentials compared with the intact arm.

In 12 out of 13 patients of group 1 the N20 potential was absent with stimulation of the injured arm. The remaining record was classified as

Table 1 Mean values for the amplitude and latency ( \pm one standard deviation) of three evoked potentials in 10-14 normal subjects, equal stimulus intensity (constant voltage) applied to the median nerve at either wrist. The largest difference encountered between left and right stimulation in any individual is expressed as a percentage of the amplitude or latency on the side with the larger or earlier response

\begin{tabular}{|c|c|c|c|c|c|}
\hline \multirow[t]{2}{*}{ Potential } & & \multirow{2}{*}{$\begin{array}{l}\text { Amplitude }(\mu V) \\
\text { Mean } \pm S D\end{array}$} & \multirow{2}{*}{$\begin{array}{l}\text { Latency }(m s) \\
\text { Mean } \pm S D\end{array}$} & \multicolumn{2}{|c|}{ Largest individual left/right difference } \\
\hline & & & & Amplitude \% & Latency $\%$ \\
\hline $\begin{array}{l}\text { N9 } \\
\text { (clavicle, } n=10 \text { ) } \\
\text { N13 } \\
\text { (Cv2. } n=14 \text { ) } \\
\text { N20 } \\
\text { (scalp, } n=13 \text { ) }\end{array}$ & $\begin{array}{l}\mathbf{L} \\
\mathbf{R} \\
\mathbf{L} \\
\mathbf{R} \\
\mathbf{L} \\
\mathbf{R}\end{array}$ & $\begin{array}{l}8.9 \pm 5.2 \\
8.3 \pm 4.4 \\
3.1 \pm 1.5 \\
3.7 \pm 1.1 \\
1.8 \pm 1.0 \\
2.3 \pm 1.4\end{array}$ & $\begin{array}{r}9.1 \pm 0.7 \\
9.2 \pm 0.6 \\
12.4 \pm 0.7 \\
12.5 \pm 0.8 \\
18.0 \pm 1.1 \\
18.1 \pm 0.9\end{array}$ & $\begin{array}{l}40 \\
48 \\
60\end{array}$ & $\begin{array}{l}6 \\
4 \\
5\end{array}$ \\
\hline
\end{tabular}




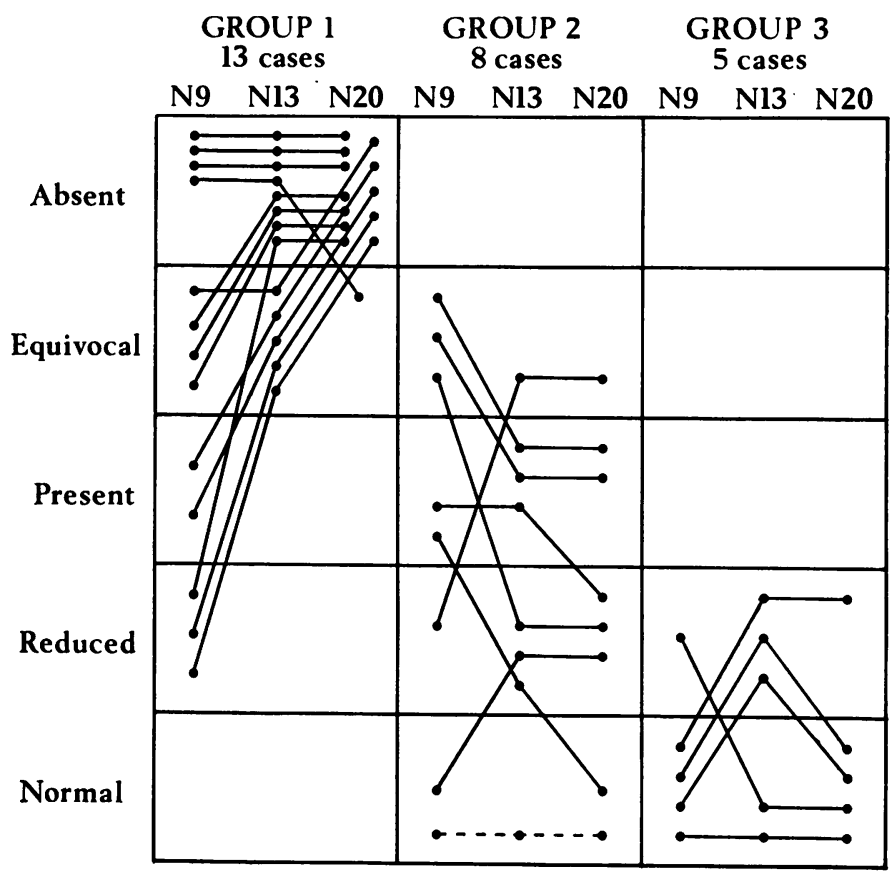

Fig. 2 Representation of the degree of attenuation of the N9, N13, and N20 potentials in 26 patients with brachial plexus traction lesions: group 1 C5-T1 root lesions, group 2 C5-C7 roots, group 3 C5-C6 roots. Potentials were classified as absent, equivocal (not identified but conceivably obscured by a small amount of muscle artefact), present (with amplitude attenuated by more than $75 \%$ compared with the intact arm), reduced (with amplitude attenuated by 40-75\%), or normal (with less than $40 \%$ attenuation). Each patient is represented by a filled circle for each potential, connected by a solid line. In one case of group 2 (broken line) all potentials were at least present but distorted by muscle artefact.

equivocal since, although the potential could not be identified, the presence of muscle artefact may have obscured a grossly attenuated response. $\mathrm{N} 13$ was absent in eight cases and equivocal in five, owing to the greater quantity of muscle artefact recorded with a neck-Fz derivation. The N9 potential was classified as absent in four cases and equivocal in four (for example, KP, Fig. 3), but in the remaining five records the potential was either "present" with amplitude attenuated by more than $75 \%$ compared with the intact arm (two cases) or "reduced" with $40-75 \%$ attenuation (three cases, for example, ABri, Fig. 3). In no case was N9 preserved with normal amplitude (less than $40 \%$ attenuation compared with the intact armthat is, within the normal range of left/right differences). In two cases where all potentials were equivocal or absent the validity of the record was questionable because of lacerations which were thought to have severed the median nerve at the time of the injury.

In group 2, N20 was present or reduced in five out of eight cases, although in one of these N20 was reduced by less than $60 \%$ which was strictly speaking within the normal range of left/right variation for this component. The $\mathrm{N} 20$ potential was equivocal in one case and normal in another, while in the remaining record (Fig. 2, broken line) all SEPs were distorted by muscle artefact although undoubtedly at least present. The N13 potential was present or reduced in six out of eight cases and equivocal in one. In five out of eight cases the attenuation of $\mathrm{N} 13$ was comparable with the attenuation of $\mathrm{N} 20$, while in two cases $\mathrm{N} 13$ was the more severely affected. The N9 potential was classified as equivocal (three cases), present with more than $75 \%$ attenuation (two cases), reduced with $40-75 \%$ attenuation (one case) or within normal limits (one case). The attenuation of N9 was comparable with that of N13 in one case only (both potentials present); in four out of eight cases N9 was the more severely affected (for example, SH, Fig. 4) while in two out of eight cases N9 was relatively preserved (for example, SW, Fig. 4).

In group $3 \mathrm{~N} 20$ was of reduced amplitude in one case only, with attenuation of about $50 \%$ which was within the normal left/right variation for this component. The N13 potential, however, was reduced in three out of five cases, and outside the normal variation of about $50 \%$. The $\mathrm{N} 13$ and N20 potentials were attenuated comparably in three out of five cases (one reduced, two normal), and in two cases N13 was the more severely affected. The $\mathrm{N} 9$ potential was classified as reduced by $40-75 \%$ in one case, and within normal limits in four. In relation to N13, N9 was unaffected comparably in one case (both potentials normal), more attenuated in one case, and less attenuated in three (for example, VM, ABru, Fig. 5).

Over all three groups, therefore, the attenuation 


\section{\begin{tabular}{lllll} 
A. Bri. Age: 20 & \multicolumn{1}{c}{ 16.5.77 } & K.P. Age:20 & 26.1.78
\end{tabular}}

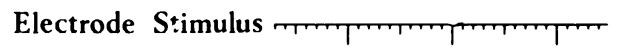
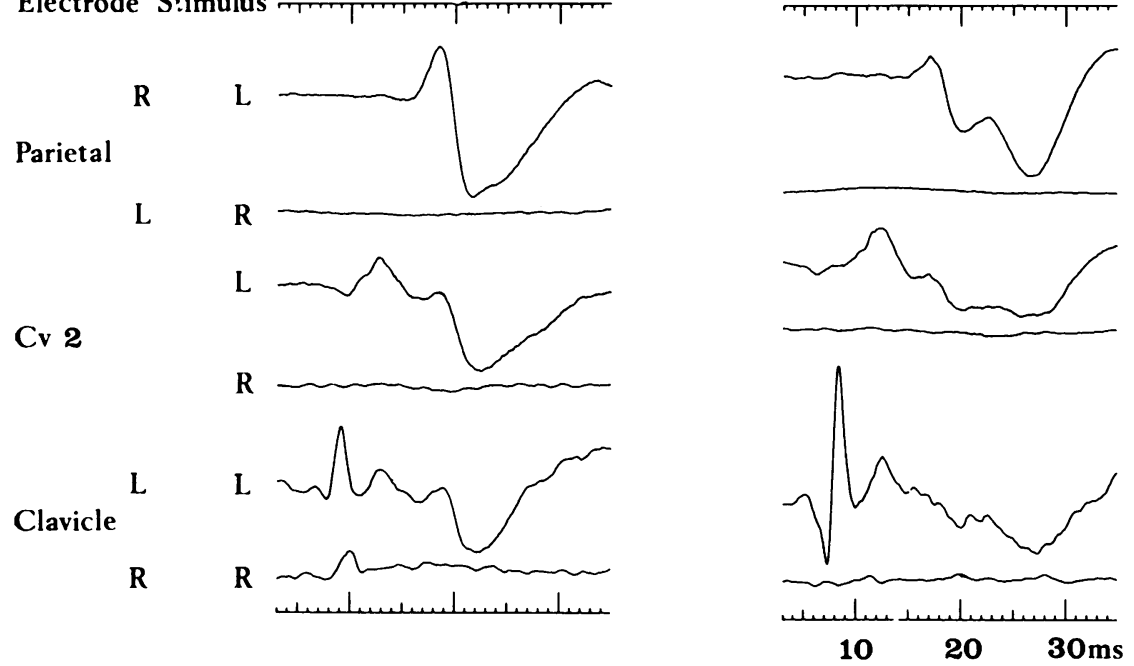

L. median

400 stimuli

R. median

800 stimuli

400 stimuli

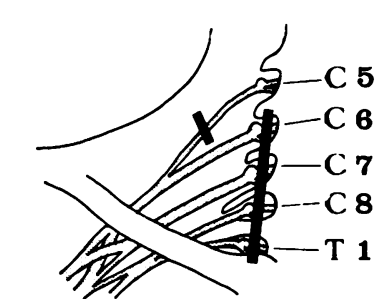

Fz reference

$+[4 \mu \mathrm{V}$

Fig. 3 Somatosensory evoked potentials in two patients with traction lesions involving the $C 5$ to $T 1$ roots (group 1). The responses to stimulation of the intact arm (left in both cases) are shown for comparison. N13 and N20 are absent for the affected arm in both records. N9 was classified as reduced for ABri (see Fig. 2) and equivocal for KP. For ABri the lesion was confirmed by exploratory surgery (see inset). The solid bars represent a rupture of the C5 root distal to the dorsal root ganglion, and a rupture of $C 6$ to $T 1$ roots proximal to the ganglia (avulsion).

of N13 was closely related to the severity of the lesion (although within normal limits in two cases), while N20 was more often within the normal amplitude range. The N9 potential was dissociated from N13, being more attenuated in five cases and less attenuated in 10; in eight records N9 and N13 were comparably attenuated, and in three the responses were of doubtful validity or obscured.

\section{FINDINGS OF SURGICAL EXPLORATION}

At operation each of the spinal nerves from C5 to $\mathrm{T} 1$ was identified, where possible. A rupture distal to the dorsal root ganglia was inferred from the presence of a stump in continuity with the spinal cord, and a more proximal rupture (pre- sumed proximal to the ganglia) from the absence of such a stump. In some proximal lesions the ganglion was identifiable, remaining attached to the avulsed root. Where a root was not discovered it was presumed avulsed. In some cases where the roots were intact there was still visible evidence of damage to the distal portion (lesion in continuity). In seven cases NAPs or SEPs or both were recorded during the operation as described in the Methods. Preoperative SEP records and the findings of the exploration are summarised in Table 3 .

In three out of five explored cases of group 1 the lesion involved all five roots from $\mathrm{C} 5$ to $\mathrm{T} 1$, while in another an extensive lesion was discovered involving the distal portion of the brachial plexus. 


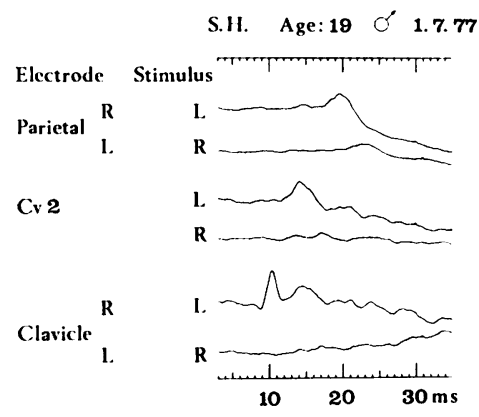

L. median R median

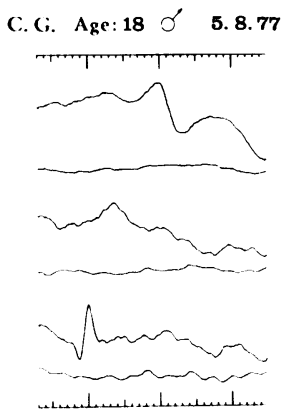

L. median 400 stimuli R. median 1200 stimuli

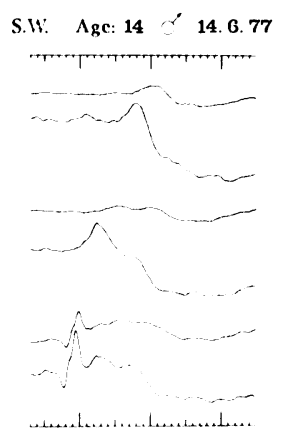

L. median 1600 stimuli R. median 800 stimuli

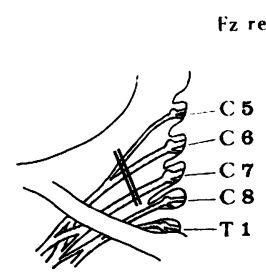

Fz reference

$+4 \mu \mathrm{V}$
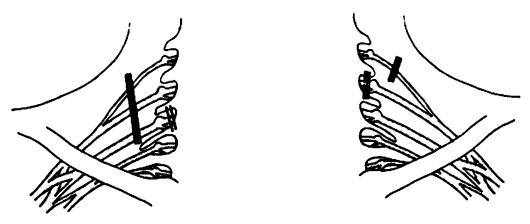

Fig. 4 Somatosensory evoked potentials in three patients with traction lesions involving the C5 to C7 roots (group 2). The responses to stimulation of the intact arm are also shown. In all three cases the lesion was confirmed by exploratory surgery (insets). A rupture distal or proximal to the dorsal root ganglia is represented by a solid bar in the appropriate location. A lesion in continuity is shown by parallel lines. For SW the C7 root was discovered to be essentially intact.

In the remaining case the $\mathrm{C} 5$ and $\mathrm{C} 6$ roots were structurally intact, although no cortical SEPs or NAPs could be recorded with stimulation of either root. An avulsion of at least three roots was discovered in four out of five explored cases, of whom the N9 potential was preserved preoperatively in three (for example, ABri, Fig. 3). In the fourth case, with N9 equivocal, an avulsion of all five roots was compounded with extensive distal involvement (BS), and in the fifth (with N9 absent) an exclusively distal lesion was found (LA). Where N9 was not abolished, however, there was no clear correlation between the degree of attenuation and the visible extent of distal involvement.

In group 2 the lesion involved the $\mathrm{C} 5$ to $\mathrm{C} 7$ roots in three out of four explored cases, while in the fourth the $\mathrm{C} 7$ root was anatomically and electrophysiologically in continuity. A distal rupture or distal lesion in continuity (CG, SH, Fig. 4) was found for both patients in whom the N9 potential had been equivocal with N13 and N20 attenuated to an equal or lesser degree. A more proximal C7 lesion, in continuity, was also suggested for CG by the absence of SEPs with stimulation of the severed $\mathrm{C7}$ stump. An avulsion of the C6 root was found for one patient (SW, Fig. 4) in whom N9 was preserved within normal limits while $\mathrm{N} 13$ and $\mathrm{N} 20$ were reduced. In this case a distal rupture of the C5 root was also found and the $\mathrm{C} 7$ root was intact (unexpectedly so in view of the clinical findings). In the last explored case (NAz) an avulsion of the $\mathrm{C} 6$ and $\mathrm{C} 7$ roots was discovered, along with a distal lesion of the $\mathrm{C} 5$ root. This was not anticipated from the preoperative record in which N9 and N13 were attenuated to a comparable degree (both potentials present) while N20 was relatively preserved.

In the single explored case of group 3 (VM, Fig. 5) the brachial plexus and spinal roots were found to be structurally intact. Nerve action potentials were present with stimulation of the exposed C5 and C6 roots, but cortical SEPs could be recorded only with stimulation of the $\mathrm{C} 7$ and $\mathrm{C} 8$ roots (T1 not attempted). The electrophysiological findings therefore suggested a lesion proximal to the C5 and C6 dorsal root ganglia, with continuity preserved possibly by the dural sheath. This was consistent with the preoperative record in which N9 was within normal limits (somewhat larger than from the intact arm) while N13 and, to a lesser degree, N20 were both attenuated.

Over all three groups a total of five cases were 


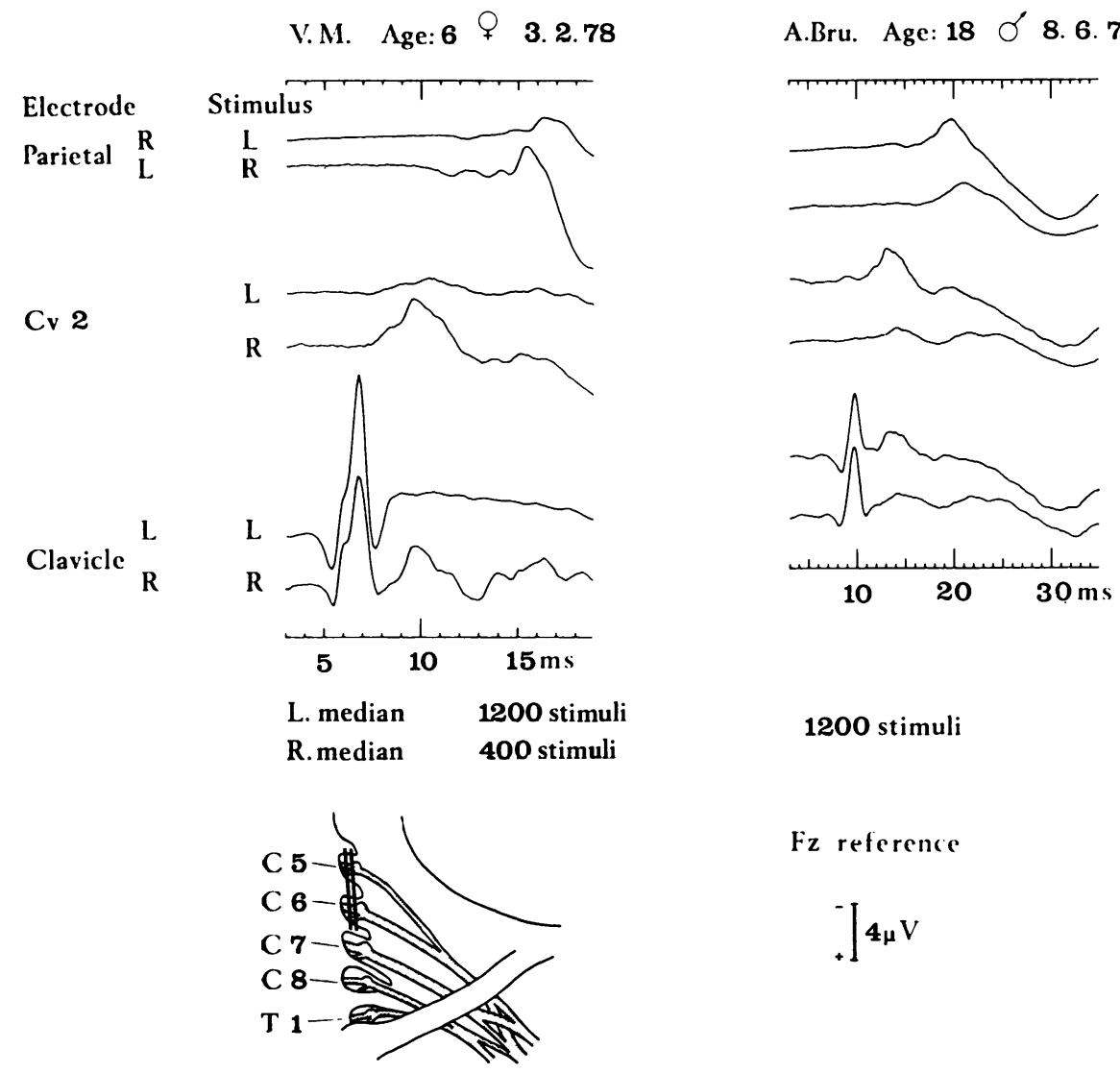

Fig. 5 Somatosensory evoked potentials in two patients with traction lesions involving the $C 5$ and $C 6$ roots, with the responses from the intact arm for comparison. For VM a lesion in continuity (parallel lines on inset) proximal to the dorsal root ganglia of both roots was inferred from the presence of nerve action potentials and absence of cortical SEPs on stimulating the exposed roots during the exploratory operation.

explored in whom N9 had been relatively preserved compared with $\mathrm{N} 13$ which was partially or completely attenuated; a lesion involving the $\mathrm{C} 6$ or $\mathrm{C} 7$ roots or both proximal to the dorsal root ganglia was discovered in all five cases. Of the remaining five explored cases in whom the attenuation of N9 had been equal to or greater than the attenuation of N13, distal involvement of the C6 and $\mathrm{C7}$ roots was found in four, although in one case this was compounded by an avulsion of both roots.

\section{Discussion}

In traction injuries of the brachial plexus the proximity of the lesions to the spinal cord is an important factor influencing the possible extent of recovery (Drake, 1964). This is because there is as yet no capacity for restoring axonal continuity between the spinal cord and a root which has been avulsed at the point of entry, whereas with a more distal lesion regeneration of sensory and motor axons may take place, either spontaneously when anatomical continuity is preserved or aided by surgical reconstruction of ruptured nerves.

The location of the dorsal root ganglia in the spinal canal just external to the spinal cord provides a means of distinguishing between an avulsed root, with the rupture on the proximal side of the ganglion, and a more peripheral lesion. The presence of sensory action potentials in an anaesthetic arm, albeit frequently with reduced amplitude, implies a proximal lesion, since the peripheral axons are then preserved in continuity with their somata and remain in a functional condition (Bonney and Gilliatt, 1958; Warren et al., 1969). 
Table 3 Summary of the preoperative SEP record and findings at operation in 10 cases with explored brachial plexus lesions. Potentials were classified as "absent," "equivocal," "present" (attenuated by more than 75\%), "reduced" (attenuated by 40-75\%), or "normal" (attenuated by less than 40\%). NAPs and $S E P$ s referred to under Findings on exploration column were recorded at operation with stimulation of exposed spinal nerves

\begin{tabular}{|c|c|c|}
\hline Patient & $\begin{array}{l}\text { Preoperative } \\
\text { record }\end{array}$ & Findings on exploration \\
\hline \multicolumn{3}{|c|}{ Group I (C5-T1 lesions) } \\
\hline BS & $\begin{array}{l}\text { N9 equivocal } \\
\text { N13 equivocal } \\
\text { N20 absent }\end{array}$ & $\begin{array}{l}\text { C5-T1 avulsion } \\
\text { Extensive infraclavicular scarring }\end{array}$ \\
\hline $\begin{array}{l}\text { ABri } \\
\text { (See Fig. 3) }\end{array}$ & $\begin{array}{l}\text { N9 reduced } \\
\text { N13 absent } \\
\text { N20 absent }\end{array}$ & $\begin{array}{l}\text { C5 distal rupture } \\
\text { C6-T1 avulsion }\end{array}$ \\
\hline SD & $\begin{array}{l}\text { N9 present } \\
\text { N13 } \text { equivocal } \\
\text { N20 absent }\end{array}$ & $\begin{array}{l}\text { C6 distal rupture } \\
\text { C5 and C7-T1 avulsion }\end{array}$ \\
\hline $\mathrm{PH}$ & $\begin{array}{l}\text { N9 reduced } \\
\text { N13 equivocal } \\
\text { N20 absent }\end{array}$ & $\begin{array}{l}\text { C5, C6 in continuity, } \\
\text { SEPs absent } \\
\text { C7-T1 avulsion }\end{array}$ \\
\hline LA & $\begin{array}{l}\text { N9 } \text { absent } \\
\text { N13 } \text { absent } \\
\text { N20 absent }\end{array}$ & $\begin{array}{l}\text { Median nerve ruptured above } \\
\text { axilla. Extensive scarring of } \\
\text { brachial plexus }\end{array}$ \\
\hline \multicolumn{3}{|c|}{ Group 2 (C5-C7 lesions) } \\
\hline $\begin{array}{l}\text { SH } \\
\text { (See Fig. 4) }\end{array}$ & $\begin{array}{l}\text { N9 } \text { equivocal } \\
\text { N13 } \\
\text { N20 reduced } \\
\text { reduced }\end{array}$ & $\begin{array}{l}\text { C5-C7 in continuity, } \\
\text { NAPs absent }\end{array}$ \\
\hline $\begin{array}{l}\text { CG } \\
\text { (See Fig. 4) }\end{array}$ & $\begin{array}{l}\text { N9 } \\
\text { N13 } \\
\text { N20 }\end{array}$ & $\begin{array}{l}\text { C5-C7 distal rupture } \\
\text { C7 SEPs absent }\end{array}$ \\
\hline $\mathrm{NAz}$ & $\begin{array}{l}\text { N9 } \\
\text { N13 } \\
\text { present } \\
\text { N20 } \\
\text { reduced }\end{array}$ & $\begin{array}{l}\text { C5 distal rupture } \\
\text { C6, C7 avulsion }\end{array}$ \\
\hline $\begin{array}{l}\text { SW } \\
\text { (See Fig. 4) }\end{array}$ & $\begin{array}{l}\text { N9 } \text { normal } \\
\text { N13 reduced } \\
\text { N20 reduced }\end{array}$ & $\begin{array}{l}\text { C5 distal rupture } \\
\text { C6 avulsion } \\
\text { C7 intact, SEPs present }\end{array}$ \\
\hline \multicolumn{3}{|c|}{ Group 3 (C5-C6 lesions) } \\
\hline $\begin{array}{l}\text { VM } \\
\text { (See Fig. 5) }\end{array}$ & $\begin{array}{ll}\text { N9 } & \text { normal } \\
\text { N13 } & \text { reduced } \\
\text { N20 } & \text { reduced }\end{array}$ & $\begin{array}{l}\text { C5, C6 in continuity, } \\
\text { NAPs present } \\
\text { SEPs absent }\end{array}$ \\
\hline
\end{tabular}

Likewise, the presence of normal axon reflexes to subdural histamine injection is evidence that the lesion, if any, must be proximal to the sympathetic ganglia (Bonney, 1954). Motor axons, with their somata in the spinal cord, are subject to rapid degeneration after a lesion at any level (Warren et al., 1969).

Scalp-recorded SEPs have been employed previously to investigate the location of ischaemic lesions of the brachial plexus, and to monitor the progress of regenerating sensory axons, by means of stimulation at alternative sites in the arm and the axilla (Desmedt and Noel, 1973). This technique might also be employed to detect axonal regeneration after traction lesions but is not applicable to the investigation of an acute lesion since the involvement is generally more proximal than any of the available stimulation sites. Although it is useful to obtain cervical and cortical SEPs in combination with peripheral sensory nerve action potentials (Zalis et al., 1970; Rosen et al., 1977) it should be preferable to record potentials generated in structures immediately proximal and distal to the probable site of the lesion.

The N9 potential, maximally recorded over the clavicle, is believed on grounds of latency, polarity, and distribution to reflect the propagation of a mixed nerve action potential through the brachial plexus (Jones, 1977a). It is likely, therefore, that while N9 might be slightly attenuated by the degeneration of motor axons after an avulsion, as well as by the factors which may cause a reduction of amplitude of sensory nerve action potentials even when the rupture of the dorsal roots is apparently proximal to the ganglia, the potential would be abolished only by a more distal lesion. The N13 potential is thought to arise in the cervical spinal cord or possibly the brainstem (Jones, $1977 \mathrm{~b}$ ), and would be susceptible, along with the cortically generated $\mathrm{N} 20$, to a lesion on either side of the dorsal root ganglia. The attenuation of N13 compared with that of N9 should, therefore, directly reflect the degree of involvement proximal to the ganglia.

I do not propose to discuss the significance of amplitude differences between left and right arm stimulation in normal subjects, although this may be worthy of further study. It was noticeable, however, that the range of amplitude differences between left and right arm stimulation was wider for N20 than for N13, and N20 was also less susceptible to attenuation by partial brachial plexus lesions. For these reasons the N13 potential was preferred for comparison with $\mathrm{N} 9$.

In the cases drawn from group 1, with N13 and N20 predictably absent, the preservation of N9 in three out of five of those explored was found to be associated with lesions predominantly proximal to the dorsal root ganglia, while the absence of $\mathrm{N} 9$ in two out of five cases correctly foretold extensive distal involvement. In the second case illustrated in Fig. 3 (KP), N9 was classified as equivocal with $\mathrm{N} 13$ and $\mathrm{N} 20$ absent, and extensive distal involvement was, therefore, predicted. The possibility of a double lesion (as in patient BS) could not be excluded, however, and it is likely that in cases with a severe distal lesion an additional avulsion might only be detected by myelography. A similar assessment was made for five other unexplored cases from group 1, while in two further cases the definite presence of N9 with N13 and N20 absent indicated the probability of the lesion being proximal to the ganglion in at least one of the damaged roots. 
The five explored cases of groups 2 and 3 were also heterogeneous with regard to the preservation of N9 compared with N13. Of three cases in whom there was a gross attenuation of N9 with N13 affected to an equal or lesser extent a distal lesion involving the $\mathrm{C} 5$ to $\mathrm{C} 7$ roots was found in two and an avulsion of the $\mathrm{C} 6$ and $\mathrm{C} 7$ roots (with a distal rupture of the C5 root) in one case. The test, therefore, might be said to have failed in the last instance, although the presence of N9 (definite in this case, equivocal in both which were correctly assessed) might have suggested some proximal involvement. In the two remaining explored cases (one from each of groups 2 and 3) N9 was preserved compared with N13, and within normal limits compared with the intact arm. The N13 potential was also relatively spared compared with confirmed lesions involving both $\mathrm{C} 6$ and $\mathrm{C} 7$ roots. The anticipation of a lesion involving either, but not both, of the $\mathrm{C} 6$ and $\mathrm{C} 7$ roots (C6 with clinical criteria taken into account, although in SW there was also some clinical evidence of $\mathrm{C} 7$ root involvement), proximal to the dorsal root ganglion in both cases, was confirmed at operation, but the location of the C5 root lesion (distal in one case, proximal in the other) could not be foretold confidently. Of the eight unexplored cases in groups 2 and 3 a lesion proximal to the dorsal root ganglia was predicted in three with $\mathrm{N} 9$ relatively preserved compared with N13 (for example ABru, Fig. 5), while a distal lesion was indicated in three cases with the attenuation of N9 more marked than the attenuation, if any, of N13. In one case the record was obscured by muscle artefact, and in the last all potentials were within the normal amplitude range.

The results of the preoperative SEP investigation were, therefore, considered to have been of predictive value concerning the findings at operation in eight out of 10 cases, with one case in whom the avulsion was not detectable because of an extensive distal lesion, and only one in whom the preoperative indications were apparently inconsistent with the exploratory findings. With regard to possible future applications, the procedure for recording peripheral, spinal and cortical SEPs is neither invasive nor unpleasant, and requires signal amplification and averaging equipment of modest resolution and as few as two independent input channels. Although with median nerve stimulation it is likely that the majority of spinal input is via the $\mathrm{C} 6$ and $\mathrm{C} 7$ roots, an evaluation of the integrity of the $\mathrm{C} 8$ and $\mathrm{T} 1$ roots might be obtained with ulnar nerve stimulation. An aspect of the present study as yet undiscussed is the incidence of delayed potentials, particularly N13, and this may be of significance in the investigation of injuries where the brachial plexus and spinal roots are stretched but not ruptured.

The patients were under the care of Dr C. B. Wynn Parry at the Royal National Orthopaedic Hospital, London, and the exploratory operations were performed there by Dr A. Landi. I am grateful to $\operatorname{Dr} A$. M. Halliday for criticism of the manuscript, and to Mrs E. Halliday for technical assistance.

\section{References}

Bonney, G. (1954). The value of axon responses in determining the site of lesion in traction injuries of the brachial plexus. Brain, 77, 588-609.

Bonney, G., and Gilliatt, R. W. (1958). Sensory nerve conduction after traction lesion of the brachial plexus. Proceedings of the Royal Society of Medicine, 51, 365-367.

Cracco, R. Q. (1973). Spinal evoked response: peripheral nerve stimulation in man. Electroencephalography and Clinical Neurophysiology, 35, 379-386.

Davies, E. R., Sutton, D., and Bligh, A. S. (1966). Myelography in brachial plexus injury. British Journal of Radiology, 39, 362-371.

Dawson, G. D. (1947). Cerebral responses to electrical stimulation of peripheral nerve in man. Journal of Neurology, Neurosurgery, and Psychiatry, 10, 134 140.

Desmedt, J. E., and Noel, P. (1973). Average cerebral evoked potentials in the evaluation of lesions of the sensory nerves and of the central somatosensory pathway. In New Developments in Electromyography and Clinical Neurophysiology, vol. 2, pp. 352-371. Edited by J. E. Desmedt. Karger: Basel.

Drake, C. G. (1964). Diagnosis and treatment of lesions of the brachial plexus and adjacent structures. Clinical Neurosurgery, 11, 110-127.

Giblin, D. R. (1964). Somatosensory evoked potentials in healthy subjects and in patients with lesions of the nervous system. Annals of the New York Academy of Sciences, 112, 93-142.

Goff, G. D., Matsumiya, Y., Allison, T., and Goff, W. R. (1977). The scalp topography of human somatosensory and auditory evoked potentials. Electroencephalography and Clinical Neurophysiology, 42, 57-76.

Jones, S. J. (1977a). Dipolar properties and peripheral origin of the first component in the human somatosensory-evoked response. Journal of Physiology, 271, 56-57P.

Jones, S. J. (1977b). Short latency potentials recorded from the neck and scalp following median nerve stimulation in man. Electroencephalography and Clinical Neurophysiology, 43, 853-863.

Matthews, W. B., Beauchamp, M., and Small, D. G. (1974). Cervical somatosensory evoked responses in man. Nature, 252, 230-232. 
Rosen, I., Sornas, R., and Elmqvist, D. (1977). Cervical root avulsion-electrophysiological analysis with electrospinogram. Scandinavian Journal of Plastic and Reconstructive Surgery, 11, 247-250.

Warren, J., Gutmann, L., Figueroa, A. E., and Bloor, B. M. (1969). Electromyographic changes of brachial plexus root avulsions. Journal of Neurosurgery, 31, 137-140.

Zalis, A. W., Oester, Y. T., and Rodriquez, A. A. (1970). Electrophysiologic diagnosis of cervical nerve root avulsion. Archives of Physical Medicine and Rehabilitation, 51, 708-710. 